Jennifer Nagel, University of Toronto October 15, 2012

Forthcoming in Philosophy and Phenomenological Research

\title{
Defending the Evidential Value of Epistemic Intuitions: A Reply to Stich
}

Epistemology is difficult. In the ongoing struggle to improve our understanding of knowledge, epistemologists have used a variety of methods, including the method of eliciting intuitive reactions to particular cases. This method has been used for centuries, both by Western philosophers such as Plato, Augustine and Zagzebski, and by Eastern philosophers such as Dharmottara, Sriharsa and Gangesa. ${ }^{1}$ Stich contends that epistemologists have been making a mistake in using case intuitions as evidence: in his view, these responses are culturally specific and fail to reflect the nature of knowledge. In my view, intuitions about knowledge typically arise from a basic human capacity that is cross-culturally shared; namely, the capacity for folk psychology or 'mindreading'. Ordinary social interactions are supported by this capacity: we make sense of others by seeing them as thinking, wanting and knowing various things. As I see it, our intuitive capacity to detect states of knowledge is not only cross-culturally shared, but also evidentially useful for epistemology. Epistemologists can learn about knowledge by considering cases because our intuitive capacity to detect the presence and absence of knowledge is sensitive to features of knowledge that our explicit theories of knowledge have yet to capture.

Stich's reply to me argues at length that there is likely to be variation in mindreading, and therefore in epistemic intuition. However, the experimentalist challenge I aimed to address was not the experimentalist claim that there is variation in intuition: I myself emphasized that there is variation in epistemic intuition, just as there is variation in perception. My claim was rather that "epistemic intuitions do not show peculiar or particularly problematic forms of variation" (Nagel, 2012a, 27). The challenge I aimed to address, as I say on the first page of my paper, is the claim that "experimental evidence seems to point to the unsuitability of intuitions to serve as evidence at all"

\footnotetext{
${ }^{1}$ Indeed cases roughly similar to Gettier's were discussed in the Indo-Tibetan tradition as early as the $8^{\text {th }}$ century, with the shared verdict that the subject in such cases lacks knowledge (Stoltz, 2007).
} 
(Alexander \& Weinberg, 2007, 63). This is a claim to which Stich himself shows a continuing commitment: in his Reply, he characterizes experimentalists as being opposed to "the practice of using these intuitions as evidence about the nature of knowledge" (3). In what follows, I defend that practice, and argue that the variation actually found in mindreading does nothing to undercut the claim that epistemic intuitions have evidential value in epistemology.

1. What does it mean to say that epistemic intuitions are unsuitable as evidence in epistemology? Epistemologists who use case responses as evidence do not have to assume that all case intuitions must be correct; case intuitions can have evidential value even if they just generally tend to be correct. A defender of the case method can even maintain, as I have done $(2010 ; 2012 b)$, that some philosophically interesting types of scenario systematically generate mistaken intuitions, just as a defender of the legitimacy of empirical investigation can admit the existence of common and systematic perceptual illusions. ${ }^{2}$

Various arguments might be advanced to try to show that epistemic intuition is evidentially worthless: one might raise generic skeptical worries of a sort that can also be raised about sense perception. The excitement of the experimentalist challenge was its promise to give us something more than generic skepticism, its claim to deliver an empirically supported challenge to a default position of trusting epistemic intuition. Stich lays out the structure of this challenge as follows:

If one group has the intuition that the protagonist does know that $\mathrm{P}$ and the other group has the intuition that the protagonist does not know that $\mathrm{P}$, then they can't both be right. And if these group differences are found in a significant number of cases of the sort that epistemologists appeal to in debating the virtues of competing accounts of knowledge, then

\footnotetext{
2 Stich objects to my use of the Müller-Lyer array as an example of a perceptual illusion, on the grounds that a study done in 1966 suggested that the San people of the Kalahari could be immune to it. Subsequent research (e.g. Davis and Carlson 1970) casts doubt on such findings of "minimal susceptibility" or immunity to the illusion, supporting instead the milder view that there is just cross-cultural variation in its intensity. In any event, the illusion was mentioned to draw attention to the fact that consensuality and correctness may diverge-even if many people share an impression, they may be wrong-and to argue that shared illusions are a sign of shared mechanisms. Whether or not the San experience this illusion, both points still stand. Furthermore, if there is cross-cultural variation in the human capacity for estimating magnitudes visually, this is an excellent example of a cross-culturally varied capacity whose deliverances nevertheless generally have evidential value.
} 
the assumption that the content of people's intuitions in philosophically important cases are usually true is threatened, and the practice of using these intuitions as evidence about the nature of knowledge is undermined. (Stich reply, p. 3)

The first sentence here could use some refinement: Stich would be safer to say that genuine disagreement, whether between individuals or groups, indicates that the disagreeing parties can't both be right. Opposed intuitive responses to a case do not necessarily indicate genuine disagreement: if the two sides are construing a case differently, then both sides could be right about the case as each has understood it. It may take work to show that there is genuine disagreement. But assuming we find that there is genuine disagreement in 'a significant number of cases', then, according to Stich, we should refrain from using intuitions as evidence. One crucial word here is 'significant': how extensive does disagreement need to be before our epistemic intuitions lack evidential value? Those who expect intuition to be near-infallible might be disturbed by even a few instances of genuine disagreement. But those who share my more moderate expectation that intuitions have some positive evidential value would need to encounter very extensive disagreement to undermine that expectation.

For present purposes, I adopt a minimal understanding of what it means for something to have evidential value: a signal has positive evidential value as long as it raises the probability of one's hypothesis. On this understanding, to be legitimate sources of evidence, epistemic intuitions need to have a positive (not necessarily perfect) correlation with the epistemic facts. But if using something as an evidential signal requires only that it is more likely to be right than wrong, then Stich's "they can't both be right" argument will have force only if disagreement on philosophically important cases is very widespread indeed.

Two individuals who find that they have a genuine disagreement cannot both be right; equally, if the majorities in two groups show a genuine disagreement then these majorities also cannot both be right. However, not every finding of disagreement should undercut one's assumption that one is usually right. For example, in a field of judgment in which every individual 
was $95 \%$ accurate with $5 \%$ random error, anyone could expect that roughly $5 \%$ of the population would disagree with them on any given judgment, without threatening anyone's assumption of usually being right in this field. A parallel point applies to groups. Having some minority of disagreeing groups for any given judgment in some category is perfectly compatible with retaining the assumption that either one's own judgments or the judgments of one's own group are usually right in that category. Stich's basic argument will undercut the use of intuitions as evidence only if we find that others are at least as likely to disagree as to agree. (Section 4 will discuss a further argument Stich advances.)

The basic argument relies on a finding of outright disagreement rather than simply variation in the strength of agreement: if the majority of various groups are in agreement, then finding that the majority is stronger in some group than others would not in itself undercut the practice of using intuitions as evidence, any more than the finding that some groups of people have better eyesight than others would strip vision of its legitimacy as a source of evidence. In maintaining that intuitions lack evidential value, Stich is making a very strong claim: he needs to show that for philosophically interesting cases there is no significant correlation between intuitive assessments and the phenomena of interest.

Stich's own published experimental work does not support such a claim. His 2001 paper reports eleven comparisons, the majority of which support my view rather than his. ${ }^{3}$ In seven of these comparisons (64\%) the majority of participants in the contrasted groups were in agreement, and in four of these cases differences in the responses of the contrasted groups were statistically insignificant. In addition, there were two comparisons in which one group (Indian Subcontinental; Low SES) responded at 50/50 to a case while the other group (Western, high SES) gave the

\footnotetext{
${ }^{3}$ It is unfortunate that this paper discloses neither the total number of experimental participants nor the number of different ethnic groups tracked. Without this information, it is not possible to calculate the relevant Bonferroni corrections (to offset the risk of false positive results, which rise as a linear function of the number of groups differentiated). There were some ethnic groups whose group responses went unreported; apparently there were African American participants in the study, and they responded in a manner that was 'statistically indistinguishable from the WE sample' (Weinberg, p.c.).
} 
standard philosophers' response. There were only two reported comparisons (18\% of the total) in which the contrasted groups disagreed, that is, where a majority of one reported group went one way, and a majority of the other reported group went the other way. But it is only in comparisons of this last sort that Stich's question "Why should we privilege our intuitions rather than the intuitions of some other group?" has real force.

Although actual group disagreement was reported only for two out of the eleven comparisons discussed, Stich would be within his rights to note that these two comparisons concerned a Gettier case, and to remind us that Gettier cases are important in contemporary epistemology. However, we have reason to doubt that these particular results are robust. WNS tested a single Gettier case (a puzzle involving American car brands) on a single multicultural pool of American undergraduates; they found that the majority of their East Asian and South Asian participants disagreed with the majority of their Western participants in responding to this case. On their report this result was found in a single experiment; they did not test this case repeatedly, and they did not test other Gettier cases with different content. At some points WNS qualify their claims about the significance of their Gettier case finding with a nod to the possibility that their results might not replicate: "If these results are robust, then it seems that what counts as knowledge on the banks of the Ganges does not count as knowledge on the banks of the Mississippi!" (2001, 444, emphasis added). Later, however, such caution is dropped and WNS simply assert that while Western philosophers might intuitively judge that the agent of a Gettier case lacks knowledge, "most of the world's population apparently does not share these intuitions" $(2001,452)$. This confidence seems premature, and further empirical examination seems entirely appropriate.

To my knowledge the WNS disagreement results have not been replicated by others. Contrary to Stich's claim that we replicated his result, the majority of our South and East Asian participants gave the standard knowledge-denying response on this case (Nagel, San Juan, \& Mar, submitted). John Turri also reports that experimental participants recruited from India were about 
as likely as North Americans to give the standard knowledge-denying response to a Gettier case (Turri, MS).

In summary, Stich and colleagues have not presented robust evidence supporting their claim that intuitions lack evidential value. If we take all of the cases tested in their 2001 paper to be 'philosophically interesting cases', the crucial empirical premise in their argument from disagreement lacks empirical support even on their own showing. If we restrict ourselves to Gettier cases, Stich's position is supported only by one result which has failed to replicate. This is a thin basis on which to make claims about what 'the majority of the world's population' are capable of recognizing intuitively.

2. For present purposes I take no position on the extent to which the capacity to recognize knowledge is culturally transmitted. I will however observe that finding a capacity is culturally transmitted does not entail that this capacity will deliver responses that are generally inaccurate. Given the importance of mental state ascription in human communication and cooperation, it is not hard to think of reasons why there would be pressures towards accuracy in epistemic intuition in any culture-pressures to produce intuitions that knowledge is present when knowledge is in fact present. If various cultures have culturally specific ways of learning about the presence and absence of knowledge, there is no inconsistency between allowing the possibility of variation in the quality of this cultural training and expecting all cultures to do a better than random job of recognizing the presence and absence of knowledge.

The charitable assumption that all cultures are broadly on target in their intuitive epistemic judgments is supported by a variety of different types of evidence, some of which will be reviewed in the section on mindreading. But one striking piece of evidence should be mentioned at the start: the recognition of knowledge is a cross-cultural universal at least in the sense that the distinction between knowledge and mere belief is marked in all cultures. Verbs meaning KNOW and THINK (in 
the sense that embeds a propositional complement) are found in the core vocabularies of all of the languages listed in the World Loanword Database, a resource covering a variety of languages from all inhabited continents (Haspelmath \& Tadmor, 2009). These verbs are furthermore held to be lexical universals, appearing on the surprisingly short list of words said to have a precise (and typically one-word) equivalent in all natural languages (Goddard, 2010). KNOW and THINK are not universal in virtue of some status as rare technical terms: they occur with great frequency, appearing as the $8^{\text {th }}$ and $12^{\text {th }}$ most common verbs in English, and enjoying a roughly comparable ranking in other languages I have examined. Of course it is controversial, in the context of a discussion of the accuracy of epistemic intuitions, to claim that we really do have a precise equivalent for KNOW in all natural languages, but it is striking that research programs dedicated to finding the limits of cross-cultural variation in the lexicon have isolated this term as a candidate for universality. Radical inter-cultural disagreement about knowledge would make it difficult to defend any term as an equivalent for KNOW in the languages of the disagreeing cultures. A simple explanation for the universality and frequency of KNOW is that it picks out an important feature of human social reality: on this view, human beings are generally capable of gaining knowledge, and of recognizing its presence and absence in others.

The cross-linguistic universality of KNOW is compatible with considerable culturally correlated variation in what is said about knowledge. Even when they share a single concept of knowledge, different cultures and individuals could be expected to assign different extensions to this concept, given differences in background beliefs and local circumstances. Individuals with different political orientations may disagree about which websites or newspapers are better sources of knowledge. There may be specific means of generating knowledge that are familiar within some cultures but not others, such as the transmission of knowledge via electronic mail. Superficial differences of these kinds should not bar epistemologists from using intuitive judgments 
to study the deeper structural features of knowledge, although epistemologists might need to know about the relevant local conditions in designing stimuli and interpreting intuitive responses.

An understanding of the relationship between superficial differences and deeper similarities is relevant to the parallel Stich draws between linguistic and epistemic intuitions. He observes that his own intuitions about grammaticality are 'somewhat different from the intuitions of a speaker of AAVE (African American Vernacular English) and radically different from those of a monolingual Tagalog speaker' (p.9); he then suggests that I must be supposing that the mindreading capacity does not exhibit this kind of variation. Introducing the label 'universal in the strong sense' for capacities that do not exhibit the kind of variation shown in the language capacity, Stich claims that my position requires that mindreading should be 'universal in the strong sense', adding that he sees my view as holding that 'it is not enough that people in all cultures engage in mindreading, they have to do it in the same way' (ibid.).

As far as the main point is concerned, I should emphasize again that my position is not that there could be no cross-cultural variation in epistemic intuition, although I dispute Stich's claims to have found robust evidence of this variation. I am also not committed to the notion that all cultures engage in mindreading 'in the same way': cultures can tend to converge in their judgments despite taking different paths to them. It is also compatible with my position that there could be culturally correlated variation in the accuracy of epistemic intuition: some cultures could be more accurate than others, just as women are more accurate than men in certain color judgments. However, the parallel with language is potentially useful in supporting my position. The English speaker and the Tagalog speaker do not disagree with each other about the acceptability of English sentences; the Tagalog speaker has no relevant intuitions on those stimuli. The various intuitions of these two groups, however, can be studied together in order to generate a deeper understanding of the shared constraints and composition principles structuring the human capacity for language. In a similar 
spirit, epistemologists can study the structural similarities appearing in epistemic intuitions across cultures.

If epistemic intuitions generally have evidential value, we can profit directly from intuitiondriven epistemology from other cultures. For example, we can take Gangesa's $14^{\text {th-century causal }}$ theory of knowledge-a theory often guided by intuitions about particular cases (Phillips \&

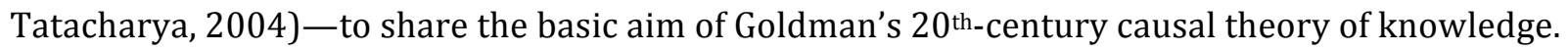
We may even discover that the medieval Indian version of the theory outperforms the newer version in certain respects (cf. Dasti \& Phillips, 2010). If Stich is right to think that intuition-driven epistemology is a 'culturally local endeavor', then we would have little to gain from looking at epistemology executed outside our own culture. On such a view there would be little more than anthropological value in reading Gangesa's discussion of a case involving a belief based on the testimony of a "perceptually deluded deceiver", who says, truly, "there is a pot there", despite believing that what he says is false (Phillips \& Tatacharya, 2004, 182). On a view which accords evidential value to epistemic intuitions across cultures, Gangesa's discussion of this case could be as valuable to our understanding of testimonial knowledge transmission as Jennifer Lackey's recent discussion of a roughly parallel case (Lackey, 2008). Indeed, there could be some special value in studying the similarity of the theoretical moves that emerge in two independent epistemological traditions in reaction to such a case.

3. I have argued that Stich has failed to produce robust evidence of disagreement in epistemic intuitions, leaving the crucial empirical premise of his basic argument unsupported. The WNS case against intuitions is not based solely on their own findings, however. In addition, they lay out a two-part story about the mechanisms that they take to underlie cross-cultural differences in epistemic intuition: (1) they speculate that epistemic intuitions are generated within cultures to endorse local strategies of reasoning and belief formation, and (2) they argue that local strategies 
are indeed problematically different across cultures, appealing to the work of Nisbett and Norenzayan on "East-West" differences in reasoning.

It is not clear what motivates suggestion (1), the suggestion that epistemic intuitions are inherently parochial and conservative in their function. There is at least a prima facie tension between this claim and the observation that most philosophers previously committed to a JTB theory shared the surprising intuition that Gettiered subjects lack knowledge. In my opinion, the fact that this intuition was antecedently unexpected is an illustration of the evidential value of intuition in epistemology: intuition can serve to rebut even entrenched theories. In order to apply the cultural chauvinism model of epistemic intuitions to explain the responses of Gettier's audience to his examples, one would need to supply some auxiliary hypotheses about what factors could have served to outweigh any cultural pressure they might have experienced as a result of their adherence to the JTB theory. WNS offer no explanation of how their cultural chauvinism model would apply in this case.

However, assuming strictly for the sake of argument that epistemic intuitions are in fact generally produced to support local strategies of reasoning, and assuming that these strategies really are diverse, these intuitions could reflect this diversity. Not every type of diversity would have to undercut the evidential value of epistemic intuitions for epistemology, however. Some kinds of diversity would be innocuous: if one society were generally more trusting than another in their reception of testimony, for example, then some intuitions about the testimonial transmission of knowledge could differ between the two societies. But this difference would not necessarily undercut the evidential value of epistemic intuitions across the board: many intuitions about inference, perception, Gettier cases and so forth could work the same way. Depending on the magnitude of the differences related to testimony, even intuitions about the epistemology of testimony might be sufficiently similar to build a common epistemological theory of testimony 
supportable by the intuitions of both cultures. The hypothetical possibility of some diversity is not on its own a threat to the evidential value of intuitions.

WNS contend that there actually are local strategies of reasoning that are problematically diverse, citing the Nisbett program. Briefly, Nisbett and colleagues maintain that there are qualitative differences in the reasoning of East Asians and Westerners, with East Asians favoring a "holistic" mode of thought and Westerners favoring an "analytic" mode of thought (Nisbett, Peng, Choi, \& Norenzayan, 2001). In their model, holistic approaches "rely on experience-based knowledge rather than on abstract logic", emphasize relationships between a focal object and the field, and are "dialectical, meaning that there is an emphasis on change, a recognition of contradiction and of the need for multiple perspectives, and a search for the "Middle Way" between opposing propositions". Analytic thought is defined as "involving detachment of the object from its context", and "the use of formal logic, and avoidance of contradiction" (ibid., 293).

The claim that East Asians rely on "experience-based knowledge" is presumably not to be taken as an indication that Westerners never do this; such claims are most charitably interpreted as describing differences in emphasis and prevalence, and indeed Nisbett and colleagues are sometimes careful to note that members of either culture have capacities for formal logic and heuristic thinking, and so forth. Formal logic and heuristic thinking are not generally opposed to each other; they often apply to different problems (e.g. explicit inference, face recognition) and even when a single problem can be tackled by either, they do not typically issue conflicting verdicts, or verdicts whose status as knowledge is obviously different (Nagel, 2011).

The most striking point of conflict between the Nisbett program's two systems concerns attitudes to contradiction, so it is worth taking a closer look at what the program says on this point. Two types of evidence were presented to support the view that East Asians were more tolerant of contradiction. The first concerned responses to dialectical proverbs such as "too humble is half proud" and "beware of your friends, not your enemies" as contrasted with proverbs lacking such 
paradoxical flair ("one against all is certain to fall"). The Asian participants in Peng and Nisbett's study liked the dialectical proverbs more than their American counterparts did, while having similar attitudes to the other proverbs (K. Peng \& R. E. Nisbett, 1999). This particular finding has not held up: later researchers attempted to reduplicate it using the same stimuli and did not find a statistically significant difference between Asians and Americans, with both groups showing similar preferences for dialectical over non-dialectical proverbs (Friedman, Chen, \& Vaid, 2006).

The second line of evidence advanced for tolerance of contradiction involved the evaluation of various diverse statements of opinion on social issues. Chinese participants showed a stronger tendency to rate conflicting statements as equally plausible, in the mid-range of a 1-5 scale, where the American participants tended to take sides, favouring one statement at the expense of the other (K. Peng \& R. Nisbett, 1999). Peng and Nisbett concluded that the Americans were following a rule that "if there is an apparent contradiction between two opposing perspectives, one must be right and the other must be wrong ... consistent with the laws of noncontradiction and the excluded middle, you cannot have it both ways", while the Chinese participants were guided by "believing that both sides of a contradiction might be right", following "the dialectical epistemology, which advocates tolerance of seeming contradiction" (K. Peng \& R. Nisbett, 1999, 749).

Various objections might be raised against this interpretation of the data. One might note that the Chinese participants certainly did not tolerate contradiction by assigning high plausibility to mutually incompatible statements. Because there is no inconsistency involved in distributing one's credence evenly over contrary opinions, both groups can be credited with avoidance of contradiction (cf. Chan, 2000). Rather than interpreting this pattern of responses as indicative of different attitudes to contradiction or fundamental qualitative differences in human reasoning, one could more plausibly see it as indicating cultural differences in open-mindedness on the particular social issues under discussion, or in the level of motivation the participants brought to the task. 
In a comprehensive survey of the cross-cultural uniformity of human reasoning (Mercier, 2011), Hugo Mercier has argued that differences found here are best explained in terms of differences in motivation. If the Western participants were more interested in the social topics selected by the American psychologist running the study, then they could be expected to invest the cognitive energy needed to take sides, a familiar result from the persuasion literature (Petty, Cacioppo, \& Goldman, 1981). Mercier argues that such differences in performance do not point to qualitative differences in underlying rational capacities, but to more superficial factors affecting activation of one system or the other in particular experimental contexts. These factors apply across the East-West divide.

Independent experimental work has lent further support to the thesis that across ethnic groups, cognitive effort gets applied when there is some incentive to apply it. The same factors work to shift Westerners and East Asians from more heuristic to more analytic ways of thinking (Zhou, He, Yang, Lao, \& Baumeister, 2012). Under similar conditions, similar tendencies towards analytic thinking are observed in both groups: Nisbett's claims that East Asians are generally weaker at formal logic and more prone to belief bias and hindsight bias have not stood up well under further empirical scrutiny (Lee, Johson-Laird, \& Sun, 2006; Pohl, Bender, \& Lachmann, 2002; Unsworth \& Medin, 2005).

Some form of the division between a heuristic and an analytic mode of thought is now widely accepted in psychology (Evans, 2007; Frankish \& Evans, 2009). Even if it is not a product of cultural background, this divide might be considered epistemologically problematic: intuitions may differ when we change from one mode of thought to the other. My own view is that intuitions do reflect such changes, and for this reason it is helpful to know about the differences between these modes of thought when interpreting the significance of various intuitions (Nagel, 2011). The suggestion that some care is needed in interpreting intuitions does not entail that intuitions lack evidential value. 
4. Stich is certainly right to point out that there are variations in mindreading across cultures, and to observe that those who hold that mindreading is cross-culturally universal are not necessarily committed to the thesis that all aspects of mindreading are executed in just the same way in all cultures. However, variation is some areas is compatible with uniformity in others: we may be uniform as far as epistemologically interesting distinctions are concerned, even if we are diverse in other ways. Variation is also compatible with universality: I am not aware of robust evidence that we are cross-culturally varied with respect to core epistemological distinctions, but if we are, this would not entail that our epistemic intuitions generally lack evidential value. What I am committed to is the thesis that intuitive knowledge attribution is cross-culturally universal-in mindreading, members of all cultures do actually attribute states of knowledge, and not just (say) states of belief and desire-and that the attribution of knowledge has not been shown to vary in ways that would eliminate the evidential value of epistemic intuitions in epistemology.

Of the diversity literature cited by Stich, Angelique Lillard's 1998 review article on cultural variation in mindreading is probably the best example to discuss, not least because it is also cited as the chief source on cultural diversity in the passages that Stich quotes from Callaghan and colleagues (2005) and from Scholl and Leslie (1999). Lillard surveys a sweeping range of material from anthropology, philosophy, semiotics and psychology on diverse attitudes to the mind, emotions, beliefs about the supernatural and so forth. Some of this material, if taken at face value, would indicate radical cross-cultural differences: for example, she reports Jane Fajans' (1985) claim that the Baining people of Papua New Guinea lack folk psychology altogether. Although Lillard distances herself from Fajans in a footnote- "the claim that they have none is probably too extreme" $(1998,13)$ - she does endorse the idea that the Baining do not talk about mental states. In a list of cultures Lillard reports as being "said to view the mind as unknowable and unimportant", the Baining appear alongside three other groups from Papua New Guinea (the Kaluli, BiminKuskusmin, the Ommura), plus the Zapotec people of Mexico, the Samoans and the Sherpas. Lillard 
summarizes the findings on these groups by saying, "for all these cultures, one would guess that mental states are believed to exist; they are simply not a topic of conversation" $(1998,13)$.

As evidence that these groups do not discuss mental states, Lillard cites sayings collected by various ethnographers, sayings such as the Kaluli people's "One cannot know what another thinks and feels", and the Zapotec "We see the fact, but do not know what is in the heart". Given that these sayings themselves attribute mental states, it seems questionable to take them as evidence of a refusal to speak of mental states. One might rather take them as acknowledgements of the difficulty of truly accurate mindreading, a difficulty also remarked upon by Western sages. Broader evidence from the cultures in question—evidence not surveyed by Lillard—shows no shortage of explicit mental state attribution. A collection of Zapotec memoirs, poems, folklore, speeches and political tracts shows ample overt discussion of states of knowing, thinking, wanting and feeling (Campbell, Binford, Barolome, \& Barabas, 1993). Baining and Kaluli songs and poetry are also rich in mental state references, although Fajans' report of an absence of folk psychology may be explained to some extent by evidence that members of both of these cultures show some reluctance to discuss their feelings with outsiders (Feld, 1990; Stebbins \& Planigale, 2011). Reference to mental states cannot be completely uncommon with outsiders, however; Arthur Capell's early handwritten lexicon of the Baining language includes only a few dozen verbs, but the verb meaning 'know' is the $9^{\text {th }}$ on this list (Capell, 1930). The Bimin-Kuskusmin of Papua New Guinea also make heavy use of verbs of thinking, knowing and feeling in describing human interactions (Poole, 1985).

Lillard's observations on diversity in the mental state lexicon are questionable. She contends that the Chewong (or Ceq Wong) people of Malaysia are "lacking a lexicalized word for think" $(1999,14)$, citing the work of Signe Howell, whose study of these people led her to identify only five mental state words, including a word for KNOW but none for THINK (Lillard, 1998, 14). More recent research suggests an oversight on Howell's part rather than a deviation on the part of 
the Chewong from cross-cultural norms: a 956-word core vocabulary list for the language does show a word for THINK, in the sense that embeds a sentential complement (Kruspe, 2009).

Differences between Japanese and European American thinking about the mind are highlighted in Lillard's article. Citing the work of Yoshihiko Ikegami, Lillard discusses linguistic differences in Japanese as a point at which "habitual use of a given language might even lead one to consider people in language specific ways" $(1998,5)$, and argues that the Japanese view of the mind offers "an entirely different conceptual landscape"; something that is "clearly different from the EASSM [European American Social Science Model] of the mind, not simply a difference in emphasis" $(1999,12)$. Such claims are difficult to reconcile with more recent empirical work on mental state attribution showing strong similarities in mental state attribution between Japanese and Western cultures. For example, a study of Japanese and American children's literature shows mental state reference occurring heavily (every 1-2 sentences) and at statistically indistinguishable rates in the two cultures, with 9 out of the 11 most common emotional and cognitive state verbs (including 'know' and 'think') the same in the two languages (Dyer-Seymour, Shatz, Wellman, \& Saito, 2004). Neuroimagining studies show a few differences in the neural implementation of mental state attribution between monolingual Americans and bilingual Japanese people, but no differences in the accuracy of their performance, either for children or adults, and even on some relatively complex problems (Kobayashi, Glover, \& Temple, 2006, 2007).

Lillard's article also discusses differences in popular beliefs about matters such as immortality and ghosts, and differences concerning the proper objects of emotions such as shame, and the categorization of various emotions in different cultures. Although much of this work is interesting, I agree with the conclusion Wellman reaches in his criticism of Lillard, in the passage cited by Stich (at p.12 of his Reply): "theory of mind research is pitched, fundamentally, at attempting to capture deeper core construals". Wellman holds that this effort "would not be 
derailed by the evidence Lillard (1998) amassed" (Wellman, 1998, 34); I take epistemology to be equally concerned with the deeper core.

Stich cites a number of authors who agree that the common basic core of mindreading is universal. However, he does not accept that knowledge attribution is a product of the common basic core. This is puzzling: most psychologists list knowledge as a mental state, alongside states of belief, desire and feeling (for a review, see Nagel, forthcoming). Knowledge attribution appears very early in human development: in the acquisition of the mental state lexicon, the verb 'know' is used earlier and more heavily than the verb 'think' (Bartsch \& Wellman, 1995; Shatz, Wellman, \& Silber, 1983). The precedence of 'know' over 'think' is apparent in languages such as Mandarin and Cantonese as well as English (Tardif \& Wellman, 2000). Stich grants that there is 'an emerging consensus that the capacity to pass the false belief task is a human universal' (p.10), but goes on to remark that 'of course, the mere capacity to pass the false belief task does not by itself enable a person to attribute knowledge in the way (or ways) that adults do; indeed it doesn't enable a person to attribute knowledge at all' (p.11).

I am not sure whether some theoretical being could pass the false belief task without being able to attribute knowledge, but human beings do not seem to do so. In the classic false belief task the child sees an agent ("Maxi") putting his chocolate in the cupboard, and then watches someone else shift the chocolate to a drawer while Maxi is absent (Wimmer \& Perner, 1983). Children are asked where Maxi will look for the chocolate when he returns, and are credited with passing when they say that Maxi will think the chocolate is in the cupboard, unaware of the transfer that took place when he was absent. But more directly, children have been asked whether Maxi knows that the chocolate is in the drawer. This question about knowledge is answered significantly earlier than the question about false belief: across cultures, the capacity to distinguish knowledge from 
ignorance seems to be a precondition of the capacity for explicit false belief attribution (Hogrefe, Wimmer, \& Perner, 1986; Wellman, 2006; Wellman \& Liu, 2004).4

Cross-cultural work on the false belief test shows that there is early development along parallel lines not only for explicit false belief, but also for knowledge attribution, even across languages that are otherwise quite different in their mental state lexicon, for example languages with a dedicated false belief verb (Shatz, Diesendruck, Martinez-Beck, \& Akar, 2003). However, one might worry about later development: a mature understanding of inference as a source of knowledge, for example, is not in place until later in childhood (Sodian \& Wimmer, 1987). A child who can tell that Maxi does not know the chocolate is in the drawer may well be unable to evaluate a complex Gettier case involving inference. Stich observes that authors strongly committed to a uniform common core of ascribed mental states also allow that there is diversity in the later application of these states. Should existing work on diversity in mature mental state ascription lead us to expect extensive cross-cultural disagreement on cases of interest to epistemologists?

Ian Apperly's work is relevant here because he has emphasized the importance of looking beyond early development to adult mental state ascription. Before examining his review of work on that frontier, it will be helpful to clarify his position on early development. As Stich observes, Apperly distinguishes between lower-level and higher-level mindreading and holds lower-level mindreading to be cross-culturally universal and shared by non-human primates. Stich is also right to point out that Apperly sees lower-level mindreading as involving only a crude, non-propositional approximation of the concept of knowledge-although Apperly has been criticized on this score (e.g. in Carruthers, 2013). But the fact that this rudimentary form of mindreading is described as universal does not imply that Apperly takes all higher-level mindreading to be culturally disparate.

\footnotetext{
${ }^{4}$ One plausible reason why knowledge attribution would be a precondition of belief attribution is that knowledge is computationally simpler, from the perspective of the ascriber. Knowledge is a mental state that essentially reflects how things are; belief is a mental state which may or may not align with reality. A more detailed discussion of the issues here, especially in light of work on "implicit false belief recognition" in infants, is a project for another occasion.
} 
In particular, any task involving explicit judgment is higher-level; this includes the knowledge vs. ignorance and explicit false belief tasks that developmental psychologists accept as cross-culturally uniform $(2011,154)$. For Apperly, both the infant's (lower-level) implicit recognition of a knowledge-like state, and the four-year-old's explicit (higher-level) attribution of knowledge to Maxi will be cross-culturally universal. Stich is right that Gettier case intuitions will not be the product of a low-level processing module, but wrong to claim that “Apperly's account of mindreading lends no support at all to the claim that the output of the mindreading system - the judgments it generates-will be cross-culturally universal when those judgments are attributions of knowledge, or when they are the attribution of any other mental state" (16). Explicit knowledge attributions on the standard mindreading tasks passed by four-year-olds are both higher-level and cross-culturally uniform.

Cross-cultural uniformity in the elementary knowledge attributions of standard mindreading tasks could nevertheless leave open the possibility of problematic diversity later on. Apperly observes that mindreading development continues in later childhood, mentioning as an example studies of 6-9 year olds' developing understanding of sarcasm and social blunders. But Apperly does not take the more advanced abilities of older children to show that they have different concepts of knowledge and belief. According to Apperly, the relevant changes in performance are traced to social expertise in applying existing concepts, rather than conceptual evolution; indeed, he contends that "it is not at all clear what would count as a more sophisticated concept of mental states than the concept of beliefs as mental representations that is routinely ascribed to young children who pass false belief tasks" $(2011,161)$.

Variations in social expertise can certainly affect the accuracy of mindreading. Stich is right to note that Apperly puts significant emphasis on the role of "social scripts and schemas" in supporting mature mental state ascription. Appperly sees mindreading as a problem that might look computationally intractable at first (anyone could think or want anything!); in practice, he 
thinks social scripts and schemas work to aid mindreading by narrowing down the range of plausible mental states in a given situation. Social scripts not only "encode information about what people typically think, know, want and intend in particular situations" $(2011,129)$, but also help focus attention on the details of the situation most likely to be relevant. But the relevance of social knowledge to mindreading does not entail deep cross-cultural disagreement. In a passage on the difficulty of mindreading in an unfamiliar culture, Apperly stresses the universality of the basic structure of mental states: "We can presume that people in all cultures operate on the same fundamental principles - we are all sentient, we all have knowledge, beliefs, desires and intentions, and these mental states interact in essentially similar ways" $(2011,165)$.

In trying to show that Apperly's account "does not suggest that adults in different cultural groups will agree in their knowledge attributions" Stich cites Apperly's discussion of the parallel between mindreading and number cognition, which is also thought to split into lower- and higherlevel processes. One of the lower-level processes is an analog function (the ANS or Approximate Number System) which allows the swift estimation of large sets of items, enabling a person to judge at a glance which of two arrays contains more dots, for example. Apperly notes that the performance of this function is variable, with greater accuracy among children who are better at 'high-level' symbolic number problems; he allows that 'it may well be that similar effects will be found for mindreading' $(2011,164)$. However, this performance variation in the ANS is not the kind of variation that would undercut the evidential value of its deliverances: to say that those who are better at symbolic number problems may give better estimates is not to concede that such estimates lack evidential value. It is not the case that the less skilled generally disagree with the more skilled in their ANS estimations (Mundy \& Gilmore, 2009). If mindreading is varied in the same way that numerical cognition is, then the evidential status of mindreading is in great shape.

If we are not generally skeptical about intuitive capacities, then we need specific reasons to discount their deliverances as evidentially worthless. Rather than speculating about the sheer 
possibility of problematic types of disagreement, one could examine existing work on these intuitive capacities and see if it tends to show commonplace variation in accuracy, or deep and extensive disagreement. As far as I can tell, existing cross-cultural work on mindreading shows accuracy variation while stressing the absence of deep disagreement. For example, in a recent study of the relationship between perspective taking and culture, Shali Wu and Boaz Keysar find significant cross-cultural differences between their Chinese and American participants: Chinese participants were swifter and more accurate in computing the perspective of a partner whose view of the scene was partially occluded. However, they do not propose that there are differences in mindreading competence here: "There is no reason to suspect that Chinese and Americans have a different understanding of the role of mental states in people's actions. ... We make a distinction between having perspective-taking ability and using this ability .. It seems that culture has its effect here at the level of use, not ability." (Keysar et al., 2003). Although they found American participants slower and less attentive, Wu and Keysar were clear that attentive participants of either culture were fully capable of executing the mindreading task, and that they were exercising a similar competence in so doing. Research of this kind does not suggest fundamental cross-cultural disagreement in knowledge attribution.

5. On what Stich describes as his "uncharitable interpretation" of my practice, I selectively discard data that are inconsistent with my view, accepting only what I "like", and seeking performance failure explanations elsewhere. There's something right about this. I do, for example, like an article which reports no gender variation in responses to a Gettier case (Wright, 2010) more than I like a conference presentation that claims otherwise (Starmans \& Friedman, 2009). But such feelings are not caprice on my part: evidence always needs to be evaluated against a background of prior knowledge, and here it matters that we have a very robust body of evidence showing an absence of significant gender variation in normal adult mindreading. Given this prior knowledge, contrary 
experimental results are likely to indicate a fluke or problem with the experiment, as indeed seems to have been the case. I was not surprised when a more recent article by the authors of the 2009 presentation reported no gender differences in Gettier case recognition. Significant new evidence can of course come to change one's background views, but it is not rational to treat all announced findings as equally plausible.

I am puzzled by the suggestion that my data fail to support my view, insofar as they show mere majority agreement, rather than perfect consensus, on philosophically standard intuitions. Given that my view is that intuitions have positive evidential relevance, data showing more than chance agreement do support my view.

When the hammer hits the ground before the feather, Newtonians do not have to abandon their account of gravitational attraction, nor do they have to throw out the data. Positing the existence of gravity is consistent with allowing the existence of air resistance. Positing a general human capacity to recognize the presence and absence of knowledge is consistent with recognizing that it may be imperfectly exercised, and imperfectly tested. Stich is right to observe that my theories about these imperfections are hesitant and speculative; however clear the signal is, I don't yet have a full theory of all the various sources of noise. Coming up with a theory would require very detailed work. It would be nice to know more about the imperfections; indeed some of my own work has been directed at figuring out what they are, and how they matter to epistemology. But it would be stultifying to proceed on the principle that all variation from a majority response must be explained before we can take the majority response to have significance.

If Stich would like to do epistemology without relying on intuitions about knowledge, he is very welcome to try to do so, but I do not think he has supplied the rest of us with good reasons to stop using epistemic intuitions as evidence. ${ }^{5}$

\footnotetext{
${ }^{5}$ For discussion and comments I am grateful to Jane Friedman, Mohan Matthen, Amia Srinivasan, Jason Stanley, Sergio Tenenbaum, Jonathan Weisberg, Tim Williamson, and participants in the NEH Summer Seminar on Experimental Philosophy at the University of Arizona.
} 


\section{References}

Alexander, J., \& Weinberg, J. M. (2007). Analytic epistemology and experimental philosophy. Philosophy Compass, 2(1), 56-80.

Apperly, I. (2011). Mindreaders: The Cognitive Basis of "Theory of Mind". Hove and New York: Psychology Press.

Bartsch, K., \& Wellman, H. (1995). Children talk about the mind. New York: Oxford University Press.

Callaghan, T., Rochat, P., Lillard, A., Claux, M. L., Odden, H., Itakura, S., Tapanya, S., \& Singh, S. (2005). Synchrony in the Onset of Mental State Reasoning. Psychological Science, 16(5), 378-384.

Campbell, H., Binford, L., Barolome, M., \& Barabas, A. (Eds.). (1993). Zapotec struggles: histories, politics, and representations from Juchitan, Oaxaca. Washington: Smithsonian Institute Press.

Capell, A. (1930). Black note book \#2: worterverzeichnis auf Baining. OLVOC. Available: http://paradisec.org.au/fieldnotes/image viewer.htm?OLVOC201,2.

Carruthers, P. (2013). Mindreading in infancy. Mind \& Language.

Chan, S. F. (2000). Formal logic and dialectical thinking are not incongruent. American Psychologist, 55(9), 1063-1064.

Dasti, M., \& Phillips, S. H. (2010). Pramāṇa Are Factive-: A Response to Jonardon Ganeri. Philosophy East and West, 60(4), 535-540.

Dyer-Seymour, J., Shatz, M., Wellman, H., \& Saito, M. (2004). Mental state expressions in US and Japanese children's books. International Journal of Behavioral Development, 28(6), 546-552.

Evans, J. (2007). Dual-processing accounts of reasoning, judgment, and social cognition. Annual Review of Psychology, 59, 255-278.

Fajans, J. (1985). The person in social context: The social character of Baining "psychology". In G. White \& J. Kirkpatrick (Eds.), Person, self, and experience: Exploring Pacific ethnopsychologies (pp. 367-397). Berkeley: University of California Press.

Feld, S. (1990). Sound and sentiment: Birds, weeping, poetics, and song in Kaluli expression (Vol. 5). Philadelphia: Univ of Pennsylvania Pr.

Frankish, K., \& Evans, J. (2009). The duality of mind: an historical perspective. In K. Frankish \& J. Evans (Eds.), In Two Minds: Dual Process Theory and Beyond (pp. 1-29). Oxford: Oxford University Press.

Friedman, M., Chen, H. C., \& Vaid, J. (2006). Proverb preferences across cultures: Dialecticality or poeticality? Psychonomic Bulletin \& Review, 13(2), 353-359.

Goddard, C. (2010). Universals and variation in the lexicon of mental state concepts. In B. Malt \& P. Wolff (Eds.), Words and the Mind (pp. 72-93). New York: Oxford University Press.

Haspelmath, M., \& Tadmor, U. (2009). World Loanword Database. Max Planck Digital Library. Available: http://wold.livingsources.org/.

Hogrefe, G. J., Wimmer, H., \& Perner, J. (1986). Ignorance versus false belief: A developmental lag in attribution of epistemic states. Child Development, 567-582.

Kobayashi, C., Glover, G. H., \& Temple, E. (2006). Cultural and linguistic influence on neural bases of "Theory of Mind": An fMRI study with Japanese bilinguals. Brain and Language, 98(2), 210-220.

Kobayashi, C., Glover, G. H., \& Temple, E. (2007). Cultural and linguistic effects on neural bases of "Theory of Mind" in American and Japanese children. Brain research, 1164, 95-107.

Kruspe, N. (2009). Ceq Wong vocabulary. Max Planck Digital Library. Available: http://wold.livingsources.org/vocabulary/26 [2012, 08-24].

Lackey, J. (2008). Learning from words: Testimony as a source of knowledge: Oxford University Press, USA.

Lee, N. Y. L., Johson-Laird, P., \& Sun, R. (2006). Are there cross-cultural differences in reasoning? Paper presented at the Proceedings of the 28th Annual Cognitive Science Conference, Vancouver.

Lillard, A. (1998). Ethnopsychologies: Cultural variations in theories of mind. Psychological Bulletin, 123(1), 332.

Mercier, H. (2011). On the universality of argumentative reasoning. Journal of Cognition and Culture, 11(1-2), 85-113.

Mundy, E., \& Gilmore, C. K. (2009). Children's mapping between symbolic and nonsymbolic representations of number. Journal of Experimental Child Psychology, 103(4), 490-502.

Nagel, J. (2010). Knowledge ascriptions and the psychological consequences of thinking about error. Philosophical Quarterly, 60(239), 286-306.

Nagel, J. (2011). The psychological basis of the Harman-Vogel paradox. Philosophers' Imprint, 11(5), 1-28. 
Nagel, J. (2012a). Intuitions and Experiments: A defense of the case method. Philosophy and Phenomenological Research.

Nagel, J. (2012b). Mindreading in Gettier cases and skeptical pressure cases. In J. Brown \& M. Gerken (Eds.), Knowledge Ascription (pp. 171-191). Oxford: Oxford University Press.

Nagel, J. (forthcoming). Knowledge as a Mental State. Oxford Studies in Epistemology.

Nagel, J., San Juan, V., \& Mar, R. (submitted). Lay Denial of Knowledge for Justified True Beliefs.

Nisbett, R., Peng, K., Choi, I., \& Norenzayan, A. (2001). Culture and systems of thought: Holistic versus analytic cognition. Psychological Review, 108(2), 291-310.

Peng, K., \& Nisbett, R. (1999). Culture, dialectics, and reasoning about contradiction. American Psychologist, 54(9), 741-754.

Peng, K., \& Nisbett, R. E. (1999). Culture, dialectics, and reasoning about contradiction. American psychologist, 54(9), 741.

Petty, R., Cacioppo, J., \& Goldman, R. (1981). Personal involvement as a determinant of argument-based persuasion. Journal of personality and social psychology, 41(5), 847-855.

Phillips, S. H., \& Tatacharya, N. (2004). Epistemology Of Perception: Gangesa's Tattvacintamani, Jewel of Reflection on the Truth (About Epistemology). New York: American Institute of Buddhist Studies.

Pohl, R. F., Bender, M., \& Lachmann, G. (2002). Hindsight bias around the world. Experimental Psychology, 49(4), 270-282.

Poole, F. J. P. (1985). Coming into social being: Cultural images of infants in Bimin-Kuskusmin folk psychology. Person, self, and experience: Exploring Pacific ethnopsychologies, 183-244.

Scholl, B. J., \& Leslie, A. M. (1999). Modularity, development and 'Theory of mind'. Mind \& Language, 14(1), 131-153.

Shatz, M., Diesendruck, G., Martinez-Beck, I., \& Akar, D. (2003). The influence of language and socioeconomic status on children's understanding of false belief. Developmental Psychology; Developmental Psychology, 39(4), 717.

Shatz, M., Wellman, H. M., \& Silber, S. (1983). The acquisition of mental verbs: A systematic investigation of the first reference to mental state. Cognition, 14(3), 301-321.

Sodian, B., \& Wimmer, H. (1987). Children's understanding of inference as a source of knowledge. Child Development, 58(2), 424-433.

Starmans, C., \& Friedman, O. (2009). Is Knowledge Subjective? A Sex Difference in Adults. Paper presented at the 6th Biennial Meeting of the Cognitive Development Society, San Antonio, Texas.

Stebbins, T., \& Planigale, M. (2011). "Explaining the Unknowable": Accessibility of Meaning and the Exegesis of Mali Baining Songs. Australian Journal of Linguistics, 30(1), 141-154.

Stoltz, J. (2007). Gettier and Factivity in Indo-Tibetan Epistemology. The Philosophical Quarterly, 57(228), 394-415.

Tardif, T., \& Wellman, H. M. (2000). Acquisition of mental state language in Mandarin-and Cantonesespeaking children. Developmental Psychology, 36(1), 25.

Turri, J. (MS). A conspicuous art: putting Gettier to the test.

Unsworth, S. J., \& Medin, D. L. (2005). Cultural differences in belief bias associated with deductive reasoning? Cognitive Science, 29(4), 525-529.

Weinberg, J. S., Nichols, S., \& Stich, S. (2001). Normativity and Epistemic Intuitions. Philosophical Topics, 29(1), 429-460.

Wellman. (2006). Scaling of theory-of-mind understandings in Chinese children, Psychological science (Vol. 17, pp. 1075).

Wellman, H. M. (1998). Culture, variation, and levels of analysis in folk psychologies: Comment on Lillard (1998).

Wellman, H. M., \& Liu, D. (2004). Scaling of Theory of Mind Tasks. Child Development, 75(2), 523-541.

Wimmer, H., \& Perner, J. (1983). Beliefs about beliefs: Representation and constraining function of wrong beliefs in young children's understanding of deception. Cognition, 13(1), 103-128.

Wright, J. C. (2010). On intuitional stability: The clear, the strong, and the paradigmatic. Cognition, 115(3), 491-503.

Zhou, X., He, L., Yang, Q., Lao, J., \& Baumeister, R. F. (2012). Control deprivation and styles of thinking. Journal of personality and social psychology, 102(3), 460-478. 